\title{
Characteristics of elderly people admitted to hospital, Part III homes, and sheltered housing
}

\author{
J. R. ALEXANDER AND A. ELDON \\ From the University of Southampton and the Southampton and South-west Hampshire Health District
}

SUMmARY Approximately 100 consecutive admissions in Southampton to sheltered housing, to Part III homes, and to long-stay geriatric hospital beds in 1975 and 1976 were selected and data were collected by interview with patients and staff. There was a total of 299 admissions in the final sample. The sheltered housing group were younger and more often married than those admitted to Part III homes, who were more often married but only slightly younger than the new geriatric patients. The three groups were separated on dependency measures with almost no overlap between the sheltered housing and the other groups, but a little more evidence of overlap and interchange between Part III and hospital admissions. The patients in hospital whose dependency scores were more typical of Part III residents were almost all special cases and this was found to be true of other apparently misplaced individuals. Most of the sheltered housing admissions were suffering from heart, chest, and musculoskeletal complaints, while new Part III residents had more psychiatric disturbance; cerebrovascular and psychiatric problems occurred most often in the hospital group. The three groups of admissions form distinct categories and it is arguable that this is a concomitant of underprovision. This also shows that there is no great measure of misplacement on the basis of the current norm, although the suitability of this norm in sheltered housing is open to question.

Long-term supervised residential care of the elderly in the public sector is undertaken for the main part in three types of institution: the geriatric hospital, the Part III home, and sheltered housing. These are administered by three separate bodies, and the amount of co-operation and co-development between them varies greatly from one area to another. It is now widely accepted that the health and social services systems should be seen as part of a total care structure for the elderly (Pasker and Ashley, 1971), and the effectiveness of the health service and local authorities in meeting this concept is a subject of increasing concern.

The part played by sheltered housing in the care of the elderly will assume increasing importance as the pressure grows on geriatric hospitals and Part III accommodation with the shifting age structure of the population. When joint schemes to meet this challenge are drawn up, it is important for the administering bodies to have reliable information about the current workload of each other's institutions in relation to the total known demand in the community. Isaacs (1969) describes a study of old people in geriatric hospital compared with a matched control group in the community. He concludes that there is a 'hard core' of old people from which geriatric patients are drawn. It is pertinent to consider whether, as pressure on the hospital system grows, an increasing number of this hard core is catered for in Part III accommodation, and whether this, in turn, results in higher dependency among sheltered housing residents.

It was against this background that in 1975 the Southampton and South-west Hampshire Geriatric Health Care Planning Team, whose members include representatives of the social service, health, and housing departments, commissioned a study to determine the characteristics of old people currently being admiited to long-stay geriatric beds, Part III homes, and sheltered housing. The comparison was to be made on the basis of age and other demographic characteristics, social and behavioural data, dependency and problem management, and clinical information. The results, viewed against the known continuum of demand, would help to assess relative deficiencies in the system, as well as pointing to any problems of misallocation and providing a baseline for future assessment and evaluation.

The study was carried out by the staff of the health district with full co-operation from the appropriate local housing and social service departments. 


\section{Methods}

The names were supplied of 100 Southampton old people consecutively admitted to sheltered housing, to Part III homes, and to long-stay geriatric and psychogeriatric hospital beds beginning in the latter half of 1975. Interviews were conducted by one of the authors (A.E.), together with two assistants from the permanent staff of the health district. Most of the old people were interviewed directly. If anyone had died, or was unable to respond adequately, the help of the caring professionals was sought in completing the questionnaire.

The questionnaire included a substantial self-care/ problem management inventory, and also asked about demographic variables and previous residence. Information was also sought about health problems related to the admissions. For sheltered housing and Part III homes, this information was extracted from the evidence supplied by a doctor on application (required in all cases). For those in hospital, the case notes were consulted. [Copies of the questionnaire are obtainable from J.A.]

The final sample consisted of 100 sheltered housing, 107 Part III, and 92 hospital admissions. Seventeen of the hospital patients were in a psychogeriatric unit. The interviews were completed during the first half of 1976.

\section{Results}

\section{BACKGROUND AND DEMOGRAPHIC} CHARACTERISTICS

Table 1 summarises the principal findings of the study. There was little difference in the age distributions of the Part III homes and hospital samples, but the sheltered housing group was substantially younger. About one-third of the total number of

Table 1 Summary of findings

\begin{tabular}{lcccc}
\hline & $\begin{array}{c}\text { Sheltered } \\
\text { housing }\end{array}$ & Part III & $\begin{array}{l}\text { Geriatric } \\
\text { unit }\end{array}$ & $\begin{array}{l}\text { Southampton } \\
\text { I971 Census }\end{array}$ \\
\hline Median age & $72 \cdot 3$ & $81 \cdot 1$ & $81 \cdot 6$ & $68 \cdot 8$ \\
\hline Male (\%) & 37 & 32 & 30 & 42 \\
\hline Married (\%) & 51 & 3 & 31 & 68 \\
Single (\%) & 5 & 14 & 11 & 32 \\
Widowed (\%) & 42 & 77 & 59 & 32 \\
Other (\%) & 1 & 6 & - & \\
\hline Previously lived alone(\%) & 32 & 46 & 23 & - \\
Psychiatric diagnosis (\%) & 3 & 25 & 33 & - \\
Depression: mean score & $3 \cdot 5$ & $3 \cdot 1$ & $3 \cdot 3$ & - \\
Confusion: mean score & $3 \cdot 7$ & $3 \cdot 2$ & $3 \cdot 0$ & - \\
Fully mobile indoors (\%) & 89 & 42 & 22 & - \\
No incontinence (\%) & 97 & 80 & 45 & - \\
Median dependency score & 17 & 40 & 54 & - \\
Barthel's Index:median & 100 & 80 & 50 & - \\
\hline Number in sample & 100 & 107 & 92 & 39000 \\
\hline
\end{tabular}

*Population 60 and over $=100 \%$. subjects were male, and this proportion did not vary greatly between the three groups.

Fifty-one per cent of those going into sheltered housing were currently married, compared with $31 \%$ of those admitted to hospital and only $3 \%$ of Part III admissions. The vast majority (77\%) of Part III admissions were widowed.

There were marked differences in the previous accommodation of the new residents (Table 2).

Table 2 Previous accommodation and temporary/ intermittent care

\begin{tabular}{llll}
\hline & $\begin{array}{l}\text { Sheltered } \\
\text { housing }\end{array}$ & Part III & $\begin{array}{l}\text { Geriatric } \\
\text { unit }\end{array}$ \\
\cline { 2 - 4 } ADMITTED FROM: & $\% \%$ & $\%$ & $\%$ \\
Home, living alone & 32 & 46 & 23 \\
Home, not alone & 63 & 30 & 56 \\
$\begin{array}{l}\text { Other } \\
\text { PREVIOUS PERIODS }\end{array}$ & 5 & 24 & 21 \\
OF CARE IN: & & & \\
Part III home & - & 11 & 6 \\
Hospital & 17 & 33 & 71 \\
\hline
\end{tabular}

Almost half of the Part III admissions were previously living alone at home, twice the proportion of geriatric patients in that category. For the sheltered housing group the proportion was about one-third. Twelve per cent of those admitted to Part III came from hospital, and $12 \%$ of those admitted to geriatric hospital came from Part III.

The current admission was viewed as permanent by the supervising staff in nearly all cases, except in hospital, where $19 \%$ were reported as admitted for temporary or intermittent care.

\section{CLINICAL INFORMATION}

Information was supplied by general practitioners in support of the applications for all Part III and sheltered housing places. For comparative purposes, the hospital case notes were consulted and principal diagnoses extracted for hospital admissions. The results are shown in Table 3.

No medical, as distinct from social, problems were mentioned for $30 \%$ of those in the sheltered housing group and $25 \%$ of the Part III group.

\section{Table 3 Clinical information}

\begin{tabular}{lccc}
\hline Diagnostic group & $\begin{array}{l}\text { Sheltered } \\
\text { housing } \\
\%\end{array}$ & $\begin{array}{l}\text { Part III } \\
\%\end{array}$ & $\begin{array}{l}\text { Geriatric } \\
\text { unit } \\
\%\end{array}$ \\
\hline Cerebrovascular & 8 & 5 & 29 \\
Cardiac and other vascular & 21 & 13 & 11 \\
Respiratory & 11 & 3 & 5 \\
Psychiatric & 3 & 25 & 33 \\
Musculoskeletal (non-traumatic) & 19 & 10 & 9 \\
Trauma & 1 & 5 & 13 \\
Other medical & 10 & 25 & 20 \\
Social & 31 & 47 & 1 \\
\hline
\end{tabular}

GPs supplied the information for sheltered housing and Part III The hospital notes were examined for hospital cases. 
It is likely that the low proportion of social problems reported among hospital patients is an artifact of the data collection method. The clinical diagnoses for the Part III and hospital groups were similar, except for trauma $(P<0.05)$ and cerebrovascular disorders $(P<0.001)$. A substantially higher proportion of both occurred among the hospital admissions.

\section{BEHAVIOURAL ASPECTS}

Assessments of depression, confusion, aggressive behaviour and wandering characteristics were made in conjunction with the wardens, officers in charge, nursing staff and, in some cases, relatives (Table 4).

Table 4 Behavioural and psychosocial characteristics on admission

\begin{tabular}{lccc}
\hline Characteristics & $\begin{array}{c}\text { Sheltered } \\
\text { housing }\end{array}$ & Part III & $\begin{array}{l}\text { Geriatric } \\
\text { unit }\end{array}$ \\
\hline No depression & & $\%$ & \\
No confusion & 61 & 33 & 48 \\
No aggressive behaviour & 76 & 40 & 33 \\
Wandering-inside & 96 & 84 & 84 \\
Wandering-outside & 1 & 12 & 28 \\
\hline
\end{tabular}

For depression, confusion, and aggression a fourpoint scale was used ( $1=$ severe, $4=$ none). In each case the sheltered housing group had a significantly lower mean score than the other two groups $(P<0.01)$. Aggressive behaviour showed a similar trend $(P<0.05)$.

The gradient from housing to hospital was clearly marked in terms of wandering tendencies, both inside $(P<0.01)$ and outside $(P<0.05)$.

Mobility and incontinence, two variables with important implications for patient management, showed highly significant differences. While $89 \%$ of sheltered housing, $42 \%$ of Part III, and $22 \%$ of hospital admissions were fully mobile indoors, $4 \%$ of sheltered housing, $1 \%$ of Part III, and $28 \%$ of hospital admissions were totally dependent on the help of another person. A further. $11 \%$ in hospital were totally immobile.

Incontinence of urine and faeces during the day and at night were assessed on a three-point scale (Table 5). More than one-third of new admissions to hospital were doubly incontinent in the daytime. Incontinence affected only a very small number of old people in the other groups.

Table 5 Assessment of incontinence

\begin{tabular}{lccc}
\hline Site and time of incontinence & $\begin{array}{c}\text { Sheltered } \\
\text { housing }\end{array}$ & Part III & $\begin{array}{c}\text { Geriatric } \\
\text { unit }\end{array}$ \\
\hline Urine (night) & 3 & 9 & 55 \\
Urine (day) & 2 & 4 & 50 \\
Faeces (night) & 1 & 3 & 39 \\
Faeces (day) & 1 & 3 & 37 \\
\hline
\end{tabular}

DEPENDENCY

Seventeen self-care items were included in the interview schedule, each assessed on a scale from 1 (no difficulty) to 4 (could not do). The items are listed in Table 6. The scores were treated in three

Table 6 Dependency scale and mean score for each of the three groups

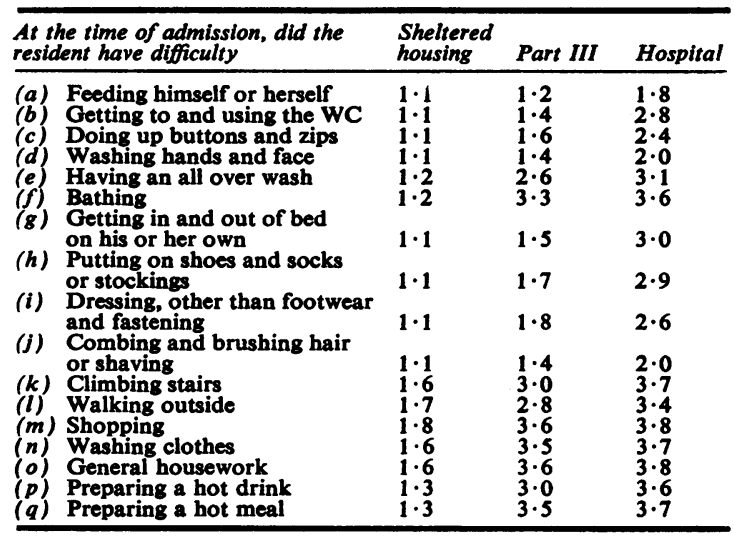

*Items were assessed as follows: $1=$ no difficulty $2=$ slight difficulty $3=$ needed some assistance $4=$ could not do.

ways. Firstly, a simple additive score was obtained; secondly, the Barthel Index was calculated for each case (Wylie and White, 1964; Wylie, 1967); thirdly, stepwise discriminant analysis was used to identify variables important in discriminating between the groups.

Fig. 1 shows the relative frequency distribution of

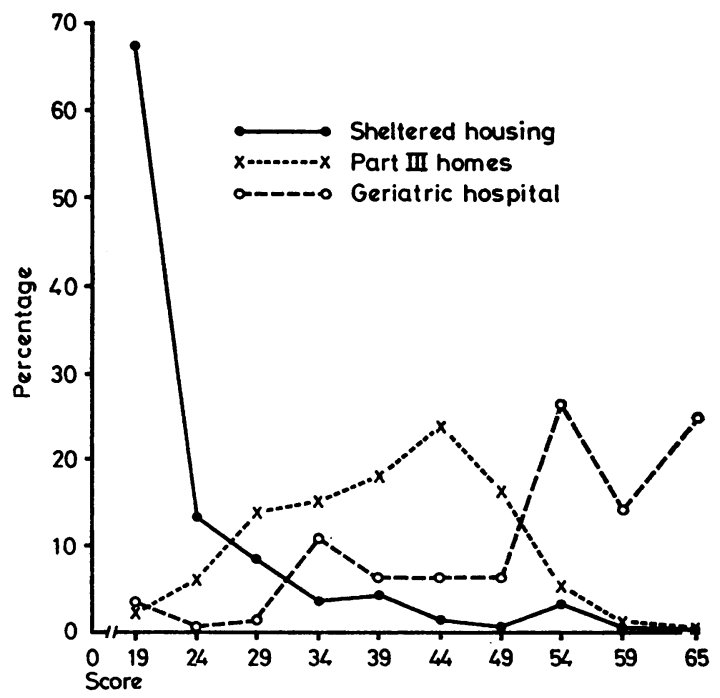

Fig. 1 Dependency scores distribution. 
dependency scores for the three groups $(17=$ minimum, $68=$ maximum). There is a very marked difference in the distribution of scores between the three groups. Sixty-four per cent of the sheltered housing group scored the minimum, and $90 \%$ of them scored less than 35 . Only $10 \%$ of the Part III group scored more than 50; the corresponding decile for the hospital group was 65 . The cumulative distributions are shown in Fig. 2, in which the

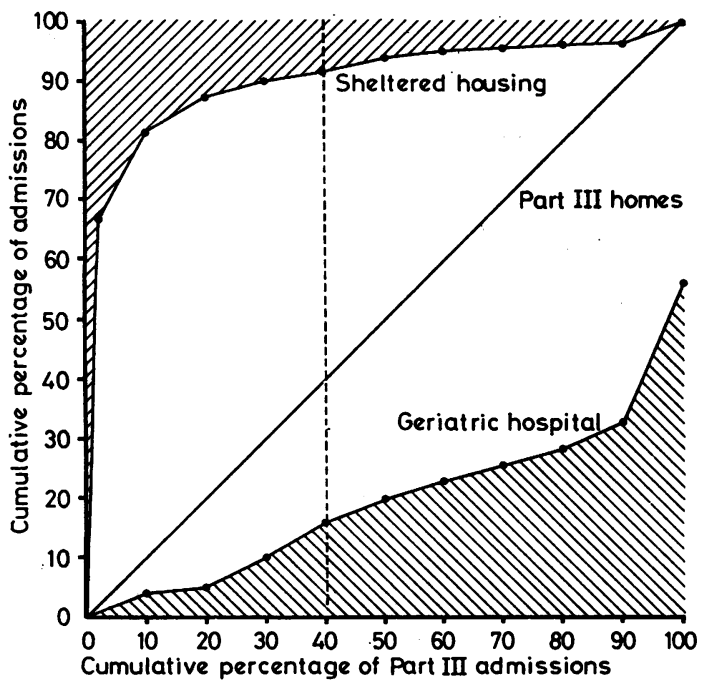

Fig. 2 Cumulative distributions.

horizontal axis has been transformed so that the Part III curve becomes a diagonal line. From this it can be seen, for example, that the $40 \%$ least dependent in Part III had scores similar to $91 \%$ of housing admissions, but to only $16 \%$ of hospital admissions. The size of the shaded areas represents the degree of overlap between the Part III and the other two distributions.

The Barthel Index is a standard measure of dependence developed for use in rehabilitation studies of stroke patients. A score of 100 represents total independence. A patient with a score of 0 is totally dependent in each of the self-care/management variables included (Table 7). The distribution of the Index for the three groups is summarised in Table 8. The overall distinctness of the three groups is again strongly marked.

Stepwise discriminant analysis was used to discover the best single variable, or pair of variables, or group of variables, to distinguish between the groups. The best single discriminator was the ability to prepare a hot drink; this showed the greatest difference between the sheltered housing
Table 7 Barthel's Index

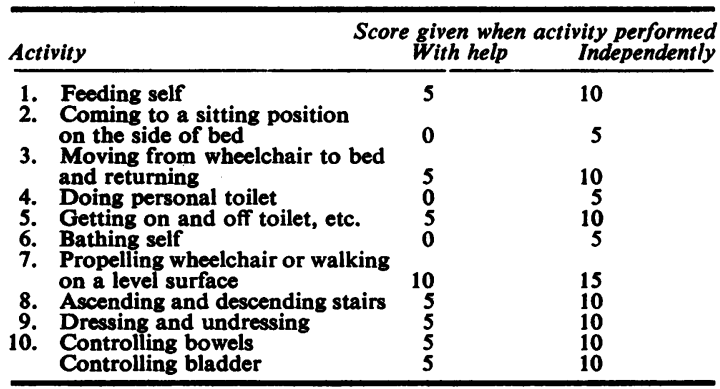

Table 8 Barthel's Index score at 25\%, 50\%, and 75\% of admissions

\begin{tabular}{llll}
\hline Group & $\begin{array}{l}\text { Lower } \\
\text { quartile }\end{array}$ & Median & $\begin{array}{l}\text { Upper } \\
\text { quartile }\end{array}$ \\
\hline Sheltered housing & 95 & 100 & 100 \\
Part III & 75 & 80 & 95 \\
Hospital & 30 & 50 & 65 \\
\hline
\end{tabular}

and other groups. The best pair of variables comprised hot drink preparation and ability to get into and out of bed. The latter variable distinguishes the Part III and hospital groups. At the third step, daytime continence of urine was found to provide the greatest additional information. By considering these three variables alone, $81 \%$ of the subjects could be correctly classified. This could not be greatly improved upon by introducing further variables.

Further investigations were made about those people $(10 \%$ overall) who appeared to be consistently misplaced on the basis of the various dependency measures considered. Almost all were found to be 'problem cases', where there were social, behavioural or clinical considerations which, in the opinion of the supervising professionals, justified their placement.

\section{Discussion}

The overall picture is of three cross-sections through a continuum of people, progressing in terms of age, health, and dependency from the sheltered housing group through to the hospital group (although the housing group were significantly younger and fitter than the other two).

Although no community sample was included in the study, it is reasonable to suppose that as people grow older they move at a faster or slower rate to higher dependency. Depending on the speed of this transition and the nature of the population, it is possible that the population distribution of dependency scores is bimodal, and in this way a distribution of dependency scores among admissions 
of the kind that we have obtained would be consistent with total provision. Of course the data are also consistent with a situation in which many people in the community fall between the sheltered housing and Part III groups that we have studied and may constitute a large unmet need. The investigation of need, demand, and supply was not part of our objectives, and a community-based survey would be necessary to inform the planners of any geriatric service shortfalls.

Nevertheless, the most striking feature of these data is the marked differences that appear between the sheltered housing and Part III entrants. The bald fact that almost two-thirds of the sheltered housing group were totally independent with respect to all the activities in our inventory indicates that unless our activity scale is insensitive, the sheltered housing group are well able to care for themselves. It is of course reasonable to question the activity scale we used, but it is worth pointing out that the items selected form a broad cross-section of activities and are consistent with those successfully used by other authors. If the sheltered housing group are as independent as they appear to be, then one must ask what the special characteristics are that make them suitable for warden supervised housing. This question must be seen in the light of the total demand on the accommodation.

The question is whether it is the oldest, sickest, or most dependent applicants who always obtain preference for places in sheltered housing, or whether other considerations, such as shortages of other types of housing, compel healthier and more able people to be admitted. Places in Part III homes and geriatric hospitals are assessed solely on the basis of clinical and social needs and the availability of adequate support in the community, but this is not the case in sheltered housing. This is administered by the housing department, which has to consider the housing needs of the whole community. The present accommodation of the applicant and its potential use for others seeking houses must be a consideration when an old person in council housing is being considered. The data we have collected may suggest a shortfall of places in the sheltered housing/Part III areas, but they are even more indicative of a shortage of unsupervised old people's housing.
The evidence on Part III and hospital provision is more consistent with a view of two institutions providing, between them, a continuum of care. The substantial movement between these institutions suggests this.

It has been suggested that a questionnaire like the one we have developed could be used as a tool in admission procedures. The work in this study indicates that it certainly could be used in this way, although whether it would provide a useful addition to procedures currently in use could only be determined by an in situ validation study. Care must be taken to ensure that 'dependency points' do not develop into an automatic and insensitive procedure. The range of individual variations shown in our $10 \%$ 'apparently misplaced' group indicates that there is no room for automatic screening procedures. Each case must be viewed independently, and this makes intercommunication and common membership of selection panels vital in the setting and maintenance of criteria. In the longer term one must look towards the setting up of a common agency for meeting the community's needs for special residential accommodation for old people.

We thank Dr. C. Godber, consultant psychogeriatrician; Mr. S. Rodwell, Southampton Division, Hampshire County Council Social Services; Mrs. M. Meadcroft, Southampton Housing Department; Mrs. Wendy Bennett; Mrs. Sue Partridge; and Miss Diane Jones.

Reprints from J. R. Alexander, Department of Community Medicine, South Academic Block, University of Southampton, Southampton SO9 4XY.

\section{References}

Isaacs, B. (1969). Some characteristics of geriatric patients. Scottish Medical Journal, 14, 243.

Pasker, P., and Ashley, J. S. A. (1971). Inter-relationship of different sectors of the total health care system. Community Medicine, 126, 272.

Wylie, C. M., and White, B. K. (1964). A measure of disability. Archives of Environmental Health, 8, 834.

Wylie, C. M. (1967). Measuring end results of rehabilitation of patients with stroke. Public Health Report, 82, 893. 